\title{
Management of non-vital anterior tooth with open apex by MTA apical plug -A case report.
}

\author{
Dr. Fahd A A Karim ${ }^{1 *}$, Dr. Kazi Hossain Mahmud¹, Dr. Asma Sultana², Dr. Shirin Sultana Chawdhari ${ }^{3}$, \\ Dr. Moktadir Hossain ${ }^{4}$, Shaihan Mohamed ${ }^{5}$, Parmina D. Costa ${ }^{5}$
}

\author{
AFFILIATION: \\ 1. Assistant professor \\ Department of Conservative Dentistry and Endodontics \\ Update Dental College and Hospitals \\ 2. Associate professor \\ Department of Science of Dental Materials \\ Update Dental College and Hospitals \\ 3. Associate professor \\ Department of Conservative Dentistry and Endodontics \\ Update Dental College and Hospitals \\ 4. Lecturer \& Dental Surgeon \\ Department of Conservative Dentistry and Endodontics \\ Update Dental College \& Hospital, Dhaka, Bangladesh \\ 5. Intern Doctor \\ Update Dental College \& Hospital, Dhaka, Bangladesh
}

\section{Article info.}

Received: $20^{\text {th }}$ October, 2018

Accepted: $10^{\text {th }}$ December, 2019

Volume: 9, Issue-1 April, 2019

DOI: https://doi.org/10.3329/updcj.v9i1.41206

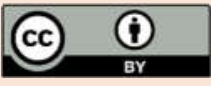

(c) Authors retain copyright and grant the journal right of first publication with the work simultaneously licensed under Creative Commons Attribution License CC - BY 4.0 that allows others to share the work with an acknowledgment of the work's authorship and initial publication in this journal.

https://creativecommons.org/licenses/by/4.0/

Publisher: Update Dental College, Dhaka, Bangladesh

Web: www.updatedentalcollege.edu.bd

E-mail: updci@hotmail.com

* Corresponding Author

Dr. Fahd A A Karim

Assistant Professor

Dept. of Conservative Dentistry and Endodontics

Update Dental College and Hospitals

Mob- 01767052475

Email: fahdkarim1792@gmail.com

\section{Citation}

Dr. Fahd A A Karim , Dr. Kazi Hossain Mahmud, Dr. Asma Sultana, Dr. Shirin Sulta Chawdhari,Dr. Muktadir Hossain Shaihan Mohamed, Parmina D. Cos Management of non-vital anterior tooth with open apex by MTA apical plug -A ca report. Update Dental College Journal. 2019 April; 9(1): 42-45 DOI: https://doi.org/10.3329/updcj.v9i1.41206

\begin{abstract}
A 15 year old boy was presented with pain in his upper anterior teeth. On clinical examination both the maxillary central incisor revealed slight discoloration and fracture of the crown. Radiographic evaluation revealed open apex of the left central incisor and apex of the right central incisor was fully developed. Apexification with MTA apical plug was carried out in left central incisor and conventional root canal treatment was done in right central incisor. In two months follow up both the tooth were clinically and radiographically asymptomatic and the healing of the apical area of the left central incisor was continued. These finding suggests that MTA can induce formation of apical barrier in the case of non-vital tooth with open apex.
\end{abstract}

\section{Keywords: MTA, Apical Pluging, Apexification}

\section{Introduction:}

Apexification is an endodontic treatment option which is done with a aim of apical repair as a hard tissue barrier across an open apex of a tooth. The treatment processes is usually used for treatment of the permanent tooth with non vital pulp and an open apex.

Complete disinfection by biomechanical preparation and three dimensional obturation of the root canal system are essential for long term endodontic success. In certain cases such as immature teeth, absence of natural apical constriction creates a challenge. One of the aims of endodontic treatment is to form an apical barrier or a stop against which one can place root canal filling material avoiding over extrusion. ${ }^{1}$

Different materials utilized in several procedures are used around the world to initiate formation of root end barrier. Calcium hydroxide with or without antiseptic, freeze dried allogenic dentin powder, bone ceramic, tricalcium phosphate, osteogenic protein, collagen, calcium gel and recently MTA and Portland cement are materials which have been used previously to see the clinical outcome to manage the tooth with open apex.. In 1999 Torabinejad and Chivian for the first time showed the use of mineral trioxide aggregate (MTA) as an apical plug ${ }^{2}$.

Apexification with MTA may be done with single visit that gives many advantages over conventional calcium hydroxide apexification which requires 5-20 months of treatment time to i form apical calcific barrier. ${ }^{3}$ This treatment modality is unpredictable, often lengthy and presents with challenges. This includes the dislodgement tendency of the coronal temporary restoration leading to re-infection. ${ }^{4}$ It also has several drawbacks like long duration of treatment time (average 12.9 months) ${ }^{5}$, very often it is difficult to recall the patients for follow-up, multiple appointments in the treatment make it delay and the risk of tooth fracture is increased the forr dressing with calcium hydroxide for long 
time. ${ }^{6}$ Considering those reasons now a days researchers around the globe suggests single visit apexification ${ }^{7}$. Hence the first choice of material, suitable for single visit apexification is Mineral trioxide aggregate..$^{4,8,9,10}$, because of it is highly biocompatible ${ }^{11,12}$, shows high bacteriostatic activity when comes in contact with body tissues ${ }^{13}$, good sealing ability leading very low micro leakage ${ }^{12}$ and as root end filling material ${ }^{12}$.

MTA helps to form the barrier at the root end root canal in teeth with necrotic pulps and open apex ${ }^{8}$ that allows the vertical condensation of fillers and sealers in the remainder of the canal.

The clinical techniques and case report are shown in which MTA was used for apexification in cases with open apex to develop an apical barrier and the effectiveness of MTA regarding those cases is well established. in this case report MTA was used for apexification tooth with open apex.

\section{Case Report:}

A 15 years old male patient with noncontributory medical history, came to the department of conservative dentistry and endodontics, Update Dental College And Hospitals, with the chief complain of pain in his upper anterior teeth \& history of trauma 2 yrs. prior to the time of reporting. He did not consult with any dentist.

Clinical examination revealed slight discoloration and fractured crown on both upper central incisors. Percussion was normal. Vitality test with ethyl chloride revealed negative result on both incisor. Radiological examination revealed an immature tooth with wide open apices on the left central incisor and closed apex on the right one.

\section{The Diagnosis :}

Left Incisor : Necrosis with open apex.

Right Incisor : Necrosis with complete apex.

The treatment plan : apexification with apical plug of MTA on the left tooth and conventional root canal treatment on the right tooth followed by composite veneer on the both incisors.

\section{Treatment procedure:}

Large straight line access cavity was prepared with round diamond bur which help to remove all the necrotic tissue from the pulp chamber. Radicular pulp was removed with barbed broach . Irrigation was done with $2.5 \%$ sodium hypochlorite and normal saline. High volume suction was used to evacuate the irrigating debris. Working length was estimated by radiographic technique within $1 \mathrm{~mm}$ of the radiographic apex and they were as, left incisor-24 $\mathrm{mm}$, right incisor $25 \mathrm{~mm}$. Gentle circumferential filing, starting with a relatively large file and progressing through the apex. canal were dried the help of sterile paper point. Calcium hydroxide mixed with glycerin

43 | P a g e (slurry mix) was placed in to the canal with Lentulo. The access cavity was filled with cotton pellet \& E-temp temporary cement. Patient was recall after one week.

Both of the tooth were symptoms free on the next visit. Access was reopened and Calcium hydroxide was flushed from left incisor with normal saline. Irrigation protocol for non vital tooth was followed. The canal was dried with sterile paper point. MTA was mixed according to manufacturers instructions and introduced in to the canal with Lentulo $1 \mathrm{~mm}$ short of the radiographic apex and condensed into the apical $1 / 3(4 \mathrm{~mm})$ by gentle packing with apical plugger $(4 \mathrm{~mm}$ short of the working length). Confirmation of apical plug with radiograph $A$ dam sterile cotton pellet was placed over the canal orifice and the access cavity was sealed with temporary filling.

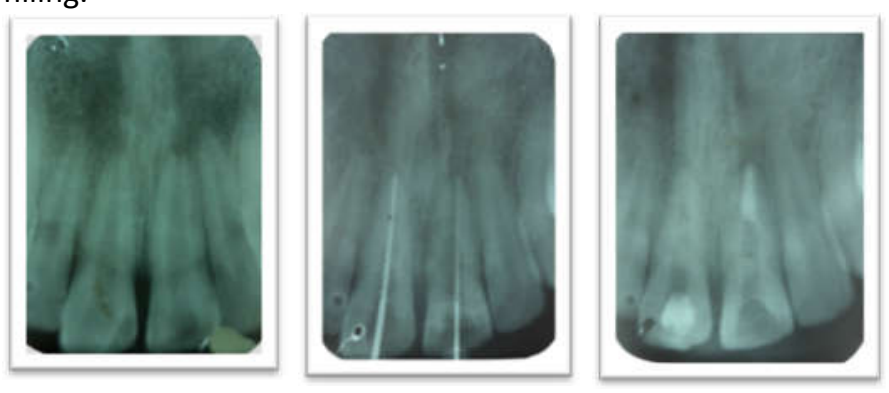

Figure-1: Initial Radiograph, Figure-2: Working Length Determination, Figure 3: MTA Plug (Figures has been arranged from left to right sequence)
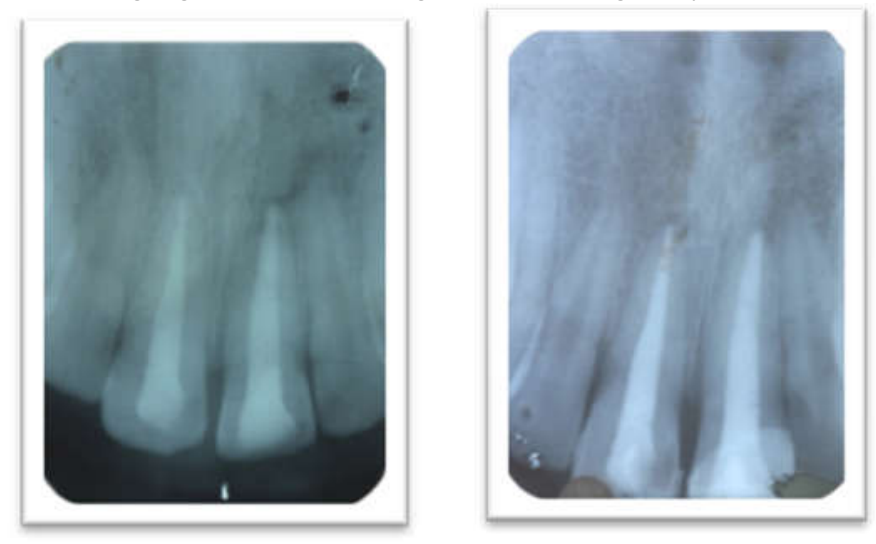

Figure-4 MTA Plug with gutta percha obturation, Figure-5 Follow Up (After 3 Months) (Figures has been arranged from left to right sequence)

On the next appointment (after 72 hours), the hardness of MTA was confirmed and the rest of the root canal was sealed with vertical condensation of gutta-percha and Sealapex root canal sealer. on the other hand ,calcium hydroxide dressing was flushed \& the canal of right incisor was obturated with vertical compaction technique on the same visit .The access filled with light cured composite. Post operative radiograph was taken to check the three dimensional obturation.

The patient was advised for recall for clinical \& radiographic evaluations after 3, 6, 12 months. 


\section{Follow-up :}

Both of the teeth was clinically and radiographically asymptomatic and healing of the apical area is continued after 3 months of the procedures.

\section{Discussion:}

An immature permanent incisor tooth is considered as a tooth with an open apex. A root end closure technique is required before Root canal treatment of these teeth so that a calcific barrier can be formed at the apex and against with which a root canal filler and sealer filling can be condensed. By this we can prevent the possibility of sealer and filler from passing through apex into the periapical areas.

Bacterial course of the infection is eliminated by root canal treatment. So irrigating solution with antimicrobial property like sodium hypochlorite and EDTA were used and intracanal medicament with potential antimicrobial activity like calcium hydroxide was placed as intra canal medicament for one week. Previous clinical studies has shown that this procedure can elimination the bacterial content in the root canal significantly within one week. $\mathrm{H}$ files were used to eliminate debris from the root canal walls but not to "shape" the canal because immature non vital permanent teeth usually have wide pulp chamber and thin dentinal walls.

Torabinejad et.al in 1990 developed MTA at Loma Linda University while working on management of tooth with open apex. MTA is usually available as two types such as grey and white MTA. MTA is composed of tricalcium silicate, tricalcium aluminate, tetracalcium aluminoferrite, calcium sulphate dehydrate and silicate oxide. Bismuth oxide is added to make the cement radioopaque. ${ }^{13} \mathrm{MTA}$ has a high $\mathrm{pH}$ of 12.5 which makes the material more antibacterial and it has a very good seating time which provide the operator enough working time. It has osteoinductive activity \& also act as cementogenic agent which helps to stimulate the immune cells. As a result the cells release lymphokines that is required for the repair \& regeneration of cementum \& stimulate bone coulpling factors necessary for bioreminaralisation and healing of osseous periapical defect ${ }^{14}$. MTA have the ability to provoke interleukin (IL) production by osteoblast that can exibit raised level of IL-1 alpha, IL-1 beta, IL-6 \& macrophage- colonystimulating factor ${ }^{11}$. The process of the biologic sealing by cementum disposition is not clear but may occur by the diffusion of calcium ions through dentinal tubules towards the root surface and inhibit bacterial colonization \& survival 15 . Both of the white \& Gray MTA are capable of inducing PDL- cell attachment regeneration, stimulate PDL fibroblasts to initiate osteogenic phenotype and promote the production of osteonectin, osteopontin \& osteoridogen \& increase alkaline phosphates level ${ }^{16,17}$ It also resist bacterial leakage against $\mathrm{E}$. faecalis, Enterobacter aerogenes, \& staphylococcus epidermidis. However Gray MTA appears better sealing agent

44 I P a g e than white, due to its less leakage property (Gray : $9.1 \%$, white : $36.4 \%$ after 42 days). Clinical studies have reported that $77 \%$ to $85 \%$ open apex healed completely 1-3 year with MTA plug ${ }^{12,18,19,20}$

As it is hydrophilic, the presence of exudate, blood or tissue fluid enhance setting. A moist cotton pellet over MTA is also indicated to achieving hermetic seal due to setting expansion. MTA has high compressive strength which is comparable to IRM and Super EBA (It reaches to maximum strength in 72 hours ${ }^{19}$ ). So usually obturation is done after 72 hours placement of MTA. Aminoshariae et al. at 2003 has shown that MTA placement by hand condensation technique results in better adaptation and leave very few voids than that of ultrasonic condensation. ${ }^{20}$ According to this, MTA was compacted in the apex using hand condensation.

Unless there is specific reasons for delay \& as one of the common cause that results in failure of apexification is the bacterial re-contamination due to loss of coronal restoration, the definitive restoration should complete as soon as possible. For more extensively damaged tooth ie. trauma, complete coronal coverage supported by post is indicated. However, In the presented case possible restoration of the access is light cured composite filling due to minimum tooth structure, requiring a durable semi permanent restoration, ease of placement \& cost.

\section{Conclusion:}

In modern clinical practice MTA has many clinical use in surgical and non surgical endodontics ranging from apexification, pulpotomy to apical surgery. The main advantages of MTA is when it is used as an apical plugin, it reduces in the number of appointments, develop a hermetic apical seal leading no micro leakage and excellent biocompatibility. This case report shows one of the indications of MTA as apexification material and it ensures that MTA can be used as an apical barrier \& considered as highly effective for treatment of immature non vital permanent teeth with open apex. Though more clinical studies with larger sample size will revel the outcome more effectively.

References:
1.Felippe Wt, Felippe MC, Rocha MJ (2006) The effect of mineral trioxide
aggregate on the apexification and periapical healing of teeth with incomplete
root formation. International Endodontic Journal 39, 2-9.
https://doi.org/10.1111/j.1365-2591.2005.01037.x PMid:16409322
2.Torabinejad M, Chivian N (1999) Clinical applications of mineral trioxide
aggregate. J Endod 25, 197-205
https://doi.org/10.1016/S0099-2399(99)80142-3
3.American Association of Endodontists (2003) Glossary of Endodontic Terms,
7th edn. Chicago: American Associati of Endodontists.
4.Maroto M, Barberia E, Planells P, Vera V: Treatment ofa non-vital immature
incisor with mineral trioxideaggregate (MTA). Dent Traumatol 2003; 19 217-
21. https://doi.org/10.1034/j.1600-9657.2003.00106.x


5.Dominguez Reyes A. Munoz Munoz L, Aznar Martin T: Studyof calcium hydroxide apexification in 26 young permanent incisors. Dent Traumatol 2005; 21, 141-145. https://doi.org/10.1111/j.1600-9657.2005.00289.x

6.Andreasen JO, Munksgaard EC, Bakland LK: Comparison of fracture resistance in root canals of immature sheep teethafter filling with calcium hydroxide or MTADentTraumatol2006;22,154-156.8.

https://doi.org/10.1111/j.1600-9657.2006.00419.x

7.Morse DR, O'Larnic J, Yesilsoy C Apexification: review of the literature. Quintessence Int 1990; 21, 589-598.

8.Torabinejad $\mathrm{M}$, Chiavian $\mathrm{N}$ : Clinical applications of mineral trioxide aggregate. J Endod 1993; 25, 197-2059.

https://doi.org/10.1016/S0099-2399(99)80142-3

9.Shabahang S, Torabinejad M: Treatment of teeth withopen apices using mineral trioxide aggregate. Practical Periodontics and Aesthetic Dentistry 2000; $12,315-20$.

10.Kho ET, Torabinejad M, Pitt Ford TR, Mc Donald, MTA stimulates a biological response in human osteolast, J Biomd Mater Res 1997; 37; 432-9. https://doi.org/10.1002/(SICI)1097-4636(19971205)37:3<432::AID-

JBM14>3.0.CO;2-D

11.KohEt, Mc Donald F, Pitt Ford TR, Torabinejad M. Cellular response to MTA J Endo 1998; 24 543-7. https://doi.org/10.1016/S0099-2399(98)80074-5

12. Holland R, Filho JA, de Souza V, Nery MJ, Bernabe PF,Junior ED: Mineral trioxide aggregate repair of lateralroot perforations. J Endod 2001; 27, 281-4. https://doi.org/10.1097/00004770-200104000-00011

13.Torabinejad M, Hong CU, Pitt Ford TR, Kettering JD:Antibacterial effects of some root end filling materials. J Endod 1995; 21, 403-6.

https://doi.org/10.1177/014572179502100502

14.Economides N, Pantelidou O.K okkas A, Tziafas D, short-term periradi cuiar tissue response to MTA as a root end filling material, Int. Endo- J 2003, 36 : 448. https://doi.org/10.1046/i.0143-2885.2003.00611.x

15. Ozdemir HO.Ozcelik B, Karabucak B, Cehreli ZC. Calcium ion diffusion from MTA through root resorption defect Dent Traumatol 2008; $24 ; 70-3$. https://doi.org/10.1111/j.1600-9657.2006.00512.x

16.Bonson S, Jeansonne BG, Lallier TE, Rootend filling material after fibroblast differentiation. J Dent Res $2004 ; 83: 408-13$.

https://doi.org/10.1177/154405910408300511 PMid:15111634

17.Fayad M1, Haw kinson R, Daniel J, Hao j. The effect of CO2 laser irradiation of PDL cell attechment to resected root surface. Oral Surg Oral Med Pathol Oral Radiol Endod 2004, 97 : 518-23.

https://doi.org/10.1016/j.tripleo.2003.10.028

18. Withersppon DE, Small JC, Regan JD, et al (2008) Retrospective analysis of open apex teeth obturated with mineral trioxide aggregate. Journal of Endodontics 34, 1171-6. https://doi.org/10.1016/j.joen.2008.07.005

PMid:18793914

19.Sluyk, Moon, Hartwell: Evaluation of setting properties and retention characteristics of mineral trioxide aggregate when used as a furcation repair material. JEndod 1998; 24, 768-71

https://doi.org/10.1016/S0099-2399(98)80171-4

20.Aminoshariac A, Hart Well GR. Moon PC (2003) Placement of MTA Using 2 different technique.J. Endo 29, 679-68

https://doi.org/10.1097/00004770-200310000-00017

45 | $P$ a g $e$ 